\title{
Third international congress on epilepsy, brain, and mind: Part 2
}

Rektor, I ; Schachter, S C ; Arya, R ; Arzy, S ; Braakman, H ; Brodie, M J ; Brugger, P ; Chang, B S ; Guekht, A ; Hermann, B ; Hesdorffer, D C ; Jones-Gotman, M ; Kanner, A M ; Garcia-Larrea, L ; Mareš, P ; Mula, M ; Neufeld, M ; Risse, G L ; Ryvlin, P ; Seeck, M ; Tomson, T ; Korczyn, A D

\begin{abstract}
Epilepsy is both a disease of the brain and the mind. Here, we present the second of two papers with extended summaries of selected presentations of the Third International Congress on Epilepsy, Brain and Mind (April 3-5, 2014; Brno, Czech Republic). Humanistic, biologic, and therapeutic aspects of epilepsy, particularly those related to the mind, were discussed. The extended summaries provide current overviews of epilepsy, cognitive impairment, and treatment, including brain functional connectivity and functional organization; juvenile myoclonic epilepsy; cognitive problems in newly diagnosed epilepsy; SUDEP including studies on prevention and involvement of the serotoninergic system; aggression and antiepileptic drugs; body, mind, and brain, including pain, orientation, the "self-location", Gourmand syndrome, and obesity; euphoria, obsessions, and compulsions; and circumstantiality and psychiatric comorbidities.
\end{abstract}

DOI: https://doi.org/10.1016/j.yebeh.2015.07.014

Posted at the Zurich Open Repository and Archive, University of Zurich

ZORA URL: https://doi.org/10.5167/uzh-115491

Journal Article

Accepted Version

Originally published at:

Rektor, I; Schachter, S C; Arya, R; Arzy, S; Braakman, H; Brodie, M J; Brugger, P; Chang, B S; Guekht, A; Hermann, B; Hesdorffer, D C; Jones-Gotman, M; Kanner, A M; Garcia-Larrea, L; Mareš, P; Mula, M; Neufeld, M; Risse, G L; Ryvlin, P; Seeck, M; Tomson, T; Korczyn, A D (2015). Third international congress on epilepsy, brain, and mind: Part 2. Epilepsy Behavior, 50:138-159.

DOI: https://doi.org/10.1016/j.yebeh.2015.07.014 


\title{
Phenomenology of phantomology: lessons from epilepsy.
}

\author{
Peter Brugger, Zurich
}

The term "Phantomology" was introduced by Polish science fiction writer Stanislaw Lem [1]. It designates the study of the virtual reality of the human body and is a visionary anticipation of modern virtual reality technologies. Used in the context of behavioral neurology, "phantomology" is the science of the body-in-the-brain [1], a body which manifests itself, on the phenomenological level, as phantom phenomena. Phantom phenomena are reported after amputation, in congenital absence of a limb [3], but also after deafferentation at all levels of the nervous system, i.e. after spinal cord injury [4] and in the course of subcortical and cortical lesions, where the propagation of somatosensory signals is interrupted at the central level, i.e. between primary sensory input areas and higher-order areas of the representation of the body as a whole. It is at this high level of disruption of bodily awareness that we can learn most from epileptic disorders. We present a selective review of the literature, with a special focus on phantom phenomena occurring with seizures.

\section{Supernumerary phantom limbs and epilepsy}

The awareness of an illusory "extra limb" is not infrequent after stroke, even if patients are sometimes reluctant to spontaneously report it [5]. Russel and Whitty [6] described three patients with a supernumerary phantom limb in traumatic epilepsy with parietal lesions. An illustrative case report of a man with new-onset attacks consisting in the experience of a left extra arm and leg was recently reported [7]. The supernumerary phantoms were the only manifestations of the seizures, whose origin could be tracked to the right parieto-temporal junction by ictal SPECT (EEG and MRI were nonlocalizing). The case report is also illustrative in a literal sense: it is accompanied by a drawing of the phantom percept sketched by the patient himself, a way of "picturing the invisible" to be preferred over artists' drawings [8].

\section{"Whole-body phantoms" and epilepsy: autoscopic phenomena}

The phenomenological classification of autoscopic phenomena [9] lists six major types: the "feeling of a presence", the autoscopic hallucination, heautoscopy, negative and inner heautoscopy and the out-of-body experience. All these subtypes of an illusory reduplication of the bodily self have been reported as an epileptic manifestation.

\section{Feeling of a presence}

The "feeling of somebody being nearby" [10] is a classic ictal phenomenon. It is most similar to the phantom limb experience in that it lacks visual quality, yet, the localization of "the other" in space is as precise as that of a phantom limb. This "invisible doppelgänger" [11] is often confined to one side of the body, but even in cases with a strictly unilateral seizure focus, the phenomenon is not necessarily lateralized [12] or is experienced ipsilesionally [13]. For the experimental evocation of a "presence" by electrocortical stimulation see ref. [14].

\section{Autoscopic hallucination and heautoscopy}

An autoscopic hallucination is the experience of seeing an image of oneself while one's observer's perspective is unambiguously centered on the body. Heautoscopy refers to the 
encounter with a double of oneself, while typically, the patient is at a loss to decide where "the real me" is located. This taxonomic distinction may seem picky, but has recently received support by lesion-symptom mappings [15]. The major lesion site is the right extrastriate cortex in autoscopic hallucinations (in accordance with focus localization in early case reports; 16; 17), but the left posterior insula and parietal cortex in heautoscopy. Insular involvement may account for the highly complex psychological interactions between patients and their doubles, whether described in the belletristic accounts of famous writers with epilepsy (ref. 18 for overview) or as reflected in the comparably dramatic contents of seizure equivalents $[19 ; 20]$. In the epilepsy literature, the distinction between these two subtypes of autoscopic phenomena is rigorously followed by some authors (e.g., 21; 22), but unfortunately not by others [23].

\section{Negative and inner heautoscopy}

Negative heautoscopy is the experience of not seeing one's body when looked at directly (or in a mirror), despite otherwise preserved visual perception. In epilepsy, the phenomenon was labeled "asomatoscopy" [24] to emphasize its conceptual similarity to asomatognosia, which is a more frequent phenomenon experienced during seizures [25]. Inner heautoscopy means the visualization of one's own internal organs in extracorporeal, peripersonal space. Phantom sensations do exist for internal organs [26], and inner heautoscopy may constitute a synesthesia-like visualization of coenesthetic sensations [27]. Modern descriptions are rare; perhaps due to mixing the phenomenon up with an entirely different phenomenon, i.e. "x-ray vision", the demonstrably false claim to see other peoples' inner organs [28].

\section{Out-of-body experiences (OBEs)}

Descriptions of OBEs have a long tradition in parapsychology [29], but scattered reports have always been around in the neuropsychiatric literature as well, especially in connection with seizure disorders $[30 ; 31]$. Neuroscientists' and philosophers' interest in phenomenon has exponentially increased [32; 33] after a seminal Nature paper in the year of 2002 [34]. This report described the experimental induction of an OBE by electrocortical stimulation over the parieto-temporal junction during presurgical epilepsy evaluation. Evoked-potential mappings during visual perception and perspective-taking tasks proved useful to pinpoint, in the healthy brain, critical stages of the experience and to delineate the mechanisms underlying various phenomenological details of an OBE [35]. In patients, methods to localize a seizure focus are similarly important to identify those neocortical structures involved in the mediation of single elements of one of the most complex phantom body experiences [36].

\section{Conclusion}

Seizure disorders provide a rich source of insight for the field of phantomology. The study of focal and complex-partial seizures reveals a broad phenomenology of altered perceptions of body and self, and seizure localization helps attributing certain symptoms to underlying neural circuits. In addition, since Wilder Penfield [37], experimental evocations of phantom phenomena in the frame of presurgical evaluations have repeatedly contributed to a better understanding of how the body is represented in the brain and how the self is hooked up with the body. Finally, the "psychiatric" components of phantom limbs and bodies are best reflected in the phenomenology of temporal-limbic seizures, and as "psychiatry is but neurology of the limbic system" (ref. 38, p.603), many apparently "purely" psychological complexities associated with autoscopic phenomena (e.g. ref. 39) may well turn out to be the expression of limbic hyperactivity. In brief, epilepsy research can formidably elucidate the varieties of extracorporeal experiences - from phantom limb to phantom body [40]. 


\section{References}

1. Lem S. Summa Technologiae. Minneapolis: University of Minnesota Press; 1964/2013.

2. Berlucchi G, Aglioti SM. The body in the brain revisited. Exp Brain Res 2010;200:25-35.

3. Brugger P, Kollias SS, Müri RM, Crelier G, Hepp-Reymond M-C, Regard M. Beyond re-membering: phantom sensations of congenitally absent limbs. Proc Natl Acad Sci USA 2000;97:6167-72

4. Curt A, Yengue CN, Hilti LM, Brugger P. Supernumerary phantom limbs in spinal cord injury. Spinal Cord 2011;49:588-595.

5. Antoniello D, Kluger BM, Sahlein DH, Heilman KM. Phantom limb after stroke: an underreported phenomenon. Cortex 2010;46:1114-1122.

6. Russel WR, Whitty CWM. Studies in traumatic epilepsy. Part 2: Focal motor and somatic sensory fits: a study of 85 cases. J Neurology Neurosurg Psychiatry 1955;16:73-97.

7. Millonig A, Bodner T, Donnemiller E, Wolf E, Unterberger I. Supernumerary phantom limb as a rare symptom of epileptic seizures - case report and literature review. Epilepsia 2011;52:e97-e100.

8. Schott GD. Revealing the invisible: the paradox of picturing a phantom limb. Brain 2014; 137:960-969.

9. Brugger P, Regard M, Landis T. Illusory reduplication of one's own body: phenomenology and classification of autoscopic phenomena. Cogn Neuropsychiatry 1997;2:19-38.

10. Ardila A, Gomez J. Paroxysmal "feeling of somebody being nearby". Epilepsia 1988;29:188-189.

11. Brugger P, Regard M, Landis T. Unilaterally felt "presences": the neuropsychiatry of one's invisible Doppelgänger. Neuropsychiatry Neuropsychol Behav Neurology 1996;9:114122.

12. Critchley M. The idea of a presence. Acta Psychiatr Neurol Scand 1955;30:155-168.

13. Rektor I, Schachter SC, Arzy S et al. Epilepsy, behavior, and art (Epilepsy, Brain, and Mind, part 1). Epilepsy Behav 2013;28:261-282.

14. Arzy S, Seeck M, Ortigue S, Spinelli L, Blanke O. Induction of an illusory shadow person. Nature 2006;443:287.

15. Heydrich L, Blanke O. Distinct illusory own-body perceptions caused by damage to posterior insula and extrastriate cortex. Brain 2013;136:790-803.

16. Genner T. Das Sehen des eigenen Spiegelbildes als epileptisches Aequivalent, Wien 
Klin Wochenschr 1947;59:656-658.

17. Maximov K. Epilepsie occipital avec hallucinations héautoscopiques. Acta Neurol Belg 1973;73:320-323.

18. Dieguez S. Doubles Everywhere: Literary Contributions to the Study of the Bodily Self. In Brain Disease and Doctors in Novels, Theater, and Film. Edited by Bogousslavsky J, Dieguez S; Basel: Karger 2013:77-115.

19. Brugger P, Agosti R, Regard M, Wieser H-G, Landis T. Heautoscopy, epilepsy and suicide. J Neurology Neurosurg Psychiatry 1994;57:838-839

20. Brugger P, Blanke O, Regard M, Bradford DT, Landis T. Polyopic heautoscopy: case report and review of the literature. Cortex 2006;42:666-674

21. Anzellotti F, Onofrj V, Maruotti V, Ricciardi L, Franciotti R, Bonanni L, Thomas A, Onofrj M. Autoscopic phenomena: case report and review of literature. Behavioral and Brain Functions 2011;7:1-11.

22. Hoepner R, Labudda K, Hoppe M, Schoendienst M, Schulz R, Tomka-Hoffmeister M, Woermann FG, Ebner A, Bien CG, Brandt C. Unilateral autoscopic phenomena as a lateralizing sign in focal epilepsy. Epilepsy Behav 2012;23:360-363.

23. Maillard L, Vignal JP, Anxionnat R, Taillandier L, Vespignani H. Semiologic value of ictal autoscopy. Epilepsia 2004;45:391-394.

24. Magri R, Mocchetti E. L' asomatoscopia (autoscopia negativa) in una epilettica. Archivo Psicol Neurol Psichiatria 1967;28:572-585.

25. Nishibayashi H, Nakai Y, Tamura M, Ogura M, Uematsu Y, Itakura T. Ictal asomatognosia due to dominant superior parietal cortical dysplasia. J Clin Neurosci 2011;18:141-142.

26. Dorpat TL. Phantom sensations of internal organs. Compr Psychiatry 1971;12:27-35.

27. Sollier P. Autoscopie interne vérifiée expérimentalement. J Psychologie Norm Pathol 1908;5:354-358.

28. Skolnick AA. Natasha Demkina: the girl with normal eyes. Skeptical Inquirer 2005;29:34-37.

29. Green C. Out-of-the-body experiences. Oxford: Institute of Psychophysical Research; 1968.

30. Vuilleumier P, Depland PA, Assal G, Regli F. [Out-of-body and astral journeys. Heautoscopy, ecstasia and experimental hallucinations of epileptic origin.] Rev Neurologique 1997;153:115-119.

31. Devinsky 0, Feldmann E, Burrowes K, Bromfield E. Autoscopic phenomena with seizures. Arch Neurology 1989;46:1080-1088. 
32. Brugger P, Mohr C. Out of the body, but not out of mind. (Editorial) Cortex 2009;45:137-140.

33. Blanke 0, Metzinger T. Full-body illusions and minimal phenomenal selfhood. Trends Cogn Sci 2009;13:7-13.

34. Blanke 0, Ortigue S, Landis T, Seeck M. Stimulating illusory own-body perceptions. Nature 2002;419:269-270.

35. Blanke O, Mohr C, Michel CM, Pacual-Leone A, Brugger P, Seeck M, Landis T, Thut G. Linking out-of-body experiences and self processing to mental own-body imagery at the temporoparietal junction. J Neurosci 2005;19:550-557.

36. Lopez C, Heydrich L, Seeck M, Blanke O. Abnormal self-location and vestibular vertigo in a patient with right frontal lobe epilepsy. Epilepsy Behav 2010;17:289-292.

37. Penfield WW, Erickson TC. Epilepsy and Cerebral Localization. Oxford: Charles C. Thomas; 1941.

38. Jaffe SL. (Letter to the editor). Neurology 2000;55:603.

39. Brugger P. Hostile interactions between body and self. Dialogues Clin Neurosci 2007;9:210-213.

40. Brugger P. From phantom limb to phantom body. Varieties of extracorporeal awareness. In Human Body Perception from the Inside Out. Edited by Knoblich G, Thornton IM, Grosjean M, Shiffrar M. Oxford: Oxford University Press; 2006:171-209. 